\title{
EPIDEMIOLOGICAL STUDY ON THE INCIDENCE OF HEARING IMPAIRMENT IN CHILDREN UP TO 3 YEARS OF AGE AND ASSOCIATED RISK FACTORS
}

\author{
Kremena K. Atanasova, \\ Georgi N. Nikolov, \\ Joana I. Simeonova ${ }^{1}$, \\ Boris I. Duhlenski
}

Department of Otorhinolaryngology, Medical University - Pleven, Bulgaria

${ }^{1}$ Department of Pharmaceutical Sciences and Social Pharmacy, Medical University -Pleven, Bulgaria

Corresponding Author:

Kremena K. Atanasova

Department of Otorhinolaryngology, Medical University - Pleven

93, V.Vazov Str.

Pleven, 5800

Bulgaria

e-mail: kr_atanassova@abv.bg

Received: May 20, 2019

Revision received: June 18, 2019

Accepted: July 30, 2019

\section{Summary}

Early diagnosis of congenital hearing impairment is of great importance to later development and social life of the affected newborns. Otoacoustic emission screening test (OAEs) is a useful tool for early evaluation of hearing in neonates and infants. Some specific risk factors (RFs) associated with prenatal, birth and early postnatal periods may influence the first screening results and further diagnostic findings. Results from OAEs in newborns in University Hospital in Pleven between 2013-2015 years are analyzed. In low birth weight children (under 2500 grams or g), and those born before the $36^{\text {th }}$ gestation week $(\mathrm{GW})$, we found deviations in the OAEs. A negative test result proved higher in newborns subjected to oxygen therapy during the first hours after birth (15.5\%), as well as in newborns with higher leucocytes count (11.0\%) or higher serum bilirubin value immediately after birth. The average birth weight of the newborns was lower in the cases with negative test results $(2848.7 \pm 506.5 \mathrm{~g})$ and unilateral negative test results ( $2823.3 \pm 535.2 \mathrm{~g})$, as compared with the group with positive test results $(3191.9 \pm 387.9 \mathrm{~g})$. Elevated bilirubin levels were more frequently established and can be expected with higher probability in low birth weight children. They shall be subject to a follow-up in time, and newborns with initial negative test result shall undergo a second test 2 months after birth. Long term monitoring is recommended for newborns with these risk factors.

Key words: neonatal hearing loss, OAEs, risk factors, low birth weight, oxygen therapy, serum bilirubin level

\section{Introduction}

According to the World Health Organization, a disabling hearing deficit is hearing loss higher than 40 decibel $(\mathrm{dB})$ for a better hearing ear in adults, and hearing loss higher than $30 \mathrm{~dB}$ for the better hearing ear in children. Globally, about 466 million people have a disabling hearing loss, and 34 million of them are children [1]. According to the statistical analysis and rate of increase it is believed that until 2050 more than 900 million people will have a disabling hearing loss - which means that 1 of each 10 people will have a hearing issue to a certain extent. According to statistical data, two-thirds of them live in developing countries (South Asia, Asia and Africa, southwards to Sahara 
Desert), which defines a potentially delayed and untimely diagnosis of hearing loss manifestation. The hearing loss levels are mild hearing loss, moderate hearing loss, severe hearing loss, and profound hearing loss. Hearing impairment can be unilateral or bilateral, and can lead to difficult communication in speech frequencies or difficult reception of high frequency sound stimulants $[1$, 2].

Fifteen-year-old children account for 9\% of the total number of 34 million children. The hearing loss that has not been diagnosed leads to an annual global expense of USD 750 billion in the healthcare sector (hearing aids excluded), for educational support, loss of work capacity and public expenses. In developing countries, children with hearing loss and deafness are rarely educated. Unemployment among adults with hearing loss is also much higher. Among employed people, a higher percentage of people with hearing loss have lower rates of employment, as compared to the general workforce. The interventions for prevention, detection and treatment of hearing deficit are cost-efficient and can lead to improved socialization of individuals affected. The earliest possible diagnostic with a minimally invasive examination is crucial for such individuals. Therefore, it determines the broad application of the otoacoustic emission screening test (OAEs) as a mandatory neonatal hearing screening test right after birth $[2,3]$.

Good hearing is of great importance for the proper neurological and psychological development of the child and their socialization. The adequate reception of the surrounding background sound is vital since birth. Of particular importance are the first six months, up to 1-2 year of development. When the hearing is impaired, the child begins to speak later, or may not speak at all.

A number of factors lead to impaired structures of the internal ear and then to hearing deficit manifestations - congenital (genetic) diseases, infections during pregnancy or during the first weeks after birth, low weight of the newborn, early gestation age, prolonged oxygen therapy, or high serum bilirubin levels [3, 4].

Several studies have been conducted in the USA $[3,5,6]$, that have shown a relationship between low weight at birth and the possibility of a hearing deficit manifestation at birth. The higher risk for such children is due to an incomplete embryonic development, in case the fetus grows more slowly in the uterus. The risk of hearing loss is highest in neonates weighing less than 1500 g. Children born during earlier gestation weeks (GWs) also have incomplete embryonic development that determines a possibility for hearing issues. The risk of sensor loss decreases significantly when the weight at birth is about 3000-3500 g. The reasons for slower intrauterine development may be related to diseases of the mother, the use of toxic medications during pregnancy, smoking, and alcohol. If the parents have a history of these risk factors, the children should be closely monitored after birth, as well as for a few months after that.

High serum bilirubin level is one of the most critical factors related to hearing analyzer. The condition has no sequelae for the majority of newborns, but lack of proper treatment may result in encephalopathy and damage of significant brain structures. The high serum bilirubin level in newborns is due to erythrocyte destruction, especially in the case of blood group incompatibility. It usually conjugates in liver cells, and in such a way can be safely released by the organism. When serum levels are extremely high, conjugation cannot be performed completely, and the non-conjugated bilirubin may pass through the blood-brain barrier $[6,7]$.

Each icterus manifested in the first 24 hours after birth can be considered as pathological. The serum levels should not exceed 239.4 nillimoles per litre $(\mathrm{mmol} / \mathrm{L})$. The most vulnerable brain structures are the auditory nuclei of the brain stem, including the cochlear nuclei. As a whole, the more the central nervous system is exposed to bilirubin, the higher the impact it will have on the hearing analyzer. Because it is not possible to determine the exposure to bilirubin, its consequences on the hearing can vary strongly, from mild hearing loss to complete deafness [8]. Children who are born prematurely and have lower weight are generally at a higher risk of impairment.

The objective of the study was to identify the risk factors (RFs) associated with the OAEs in newborns. 


\section{Materials and Methods}

A neonatal hearing screening of newborns was conducted for two years (2014-2015) on the territory of Pleven during the first days after birth before discharge from the hospital. The analysis of the results obtained took into account the presence of certain factors, considered as RFs that impact the function of the Corti organ during the first 1-6 months after birth.

The study included newborns for the followup period, considering the presence of certain RFs such as type of birth, gestational age, birth weight, oxygen therapy conducted for $\geq 3$ hours during the first days after birth, laboratory results - leukocyte number $\left(3.5 \div 10.5 \times 10^{\wedge} \mathrm{g} / \mathrm{L}\right)$, and serum bilirubin levels $(85.5 \div 239.4 \mathrm{mmol} / \mathrm{L})$

All the parents gave consent and received information about hearing loss and the benefits of screening.

During the screening, OAEs was performed initially on 935 newborns in the first stage, followed by OAEs in the second stage for newborns, who presented with hearing loss in the first stage after two months. Both ears of newborns, aged five days, were examined by an otorhinolaryngologist. The method for the OAEs entailed an earphone and a microphone that was placed in the ear, sounds were played, and the response was measured. If the hearing of a newborn was not impaired, an echo was reflected into the ear canal and measured by the microphone. When a baby had a hearing loss, no echo could be measured on the OAEs. The test took between 1 and 5 minutes in ideal conditions. In practice, the total time for testing, including discussion of the procedure with the parents, performing the test and recording the results, averages between 10 to 20 minutes.

Most of the infants who were screened positive for hearing loss were found to have a normal hearing on further diagnostic testing. Estimates of sensitivity for OAEs ranged from $80 \%$ to $98 \%$.

Data were processed with SPSS v.24.0. Tables and graphs were used to represent data. Median and mean values were used as measures of central tendency. Standard deviation (SD) and range (Min $\div$ Max) were measures of variability. The number of cases falling in each range of categorical variables and the percentage was displayed. ANOVA, Kruskal-Wallis test and Pearson Chi-square were used. We assumed the differences between groups as significant if the p-value was less than or equal to 0.05 .

\section{Results}

Distribution of the mothers and newborns by some characteristics is presented in Table 1.

Table 1. Distribution of the mothers and newborns by demographic, anthropometric and clinical characteristics

\begin{tabular}{|c|c|c|c|c|c|}
\hline Variable & Number & $\%$ & Variable & Number & $\%$ \\
\hline Maternal age & & & \multicolumn{2}{|l|}{ Place of residence } & \\
\hline Mean age $(X \pm S D)$ & $30.1 \pm 5.2$ & & City & 482 & 51.6 \\
\hline Under 20 years & 14 & 1.5 & Town & 355 & 38.0 \\
\hline $21-30$ years & 526 & 56.3 & Village & 98 & 10.5 \\
\hline $31-40$ years & 368 & 39.4 & \multirow[t]{3}{*}{ Total } & \multirow[t]{3}{*}{935} & \multirow[t]{3}{*}{100.0} \\
\hline Over 40 years & 27 & 2.9 & & & \\
\hline Total & 935 & 100.0 & & & \\
\hline Sex of newborn & & & \multicolumn{2}{|l|}{ Gestational age (GW) } & \\
\hline Male & 491 & 52.5 & Full-term newborns & 836 & 89.4 \\
\hline Female & 444 & 47.5 & Preterm newborns & 99 & 10.6 \\
\hline Total & 935 & 100.0 & \multirow{2}{*}{$\begin{array}{l}\text { Total } \\
\text { Biliruhin }\left(\mathrm{mmol}^{\prime} / \mathrm{L}\right.\end{array}$} & \multirow[t]{2}{*}{935} & 100.0 \\
\hline Birth weight & & & & & \\
\hline Average birth weight $X \pm S D$ ) & \multicolumn{2}{|l|}{$3181.7 \pm 395.9$} & Mean values (Me, Min $\div$ Max) & 172 & \\
\hline Low birth weight $(<2500 \mathrm{~g})$ & 4.6 & & Less than $85.5 \mathrm{mmol} / \mathrm{L}$ ) & $14 \div 480$ & 0.7 \\
\hline Normal birth weight $(\geq 2500 \mathrm{~g})$ & 95.4 & & Normal levels $(85.5 \div 239.4$ & 7 & 90.4 \\
\hline \multirow[t]{4}{*}{ Total } & \multirow[t]{4}{*}{100.0} & & \multirow{3}{*}{$\begin{array}{l}\mathrm{mmol} / \mathrm{L}) \\
\text { More than } 239.4 \mathrm{mmol} / \mathrm{L} \\
\text { Total }\end{array}$} & 845 & 8.9 \\
\hline & & & & 83 & 100.0 \\
\hline & & & & 935 & \\
\hline & & & Total & 935 & 100.0 \\
\hline
\end{tabular}


The average age of the mothers included in the study was $30.1 \pm 5.2$ years. The higher proportion of the newborns and mothers were in urban areas $(89.6 \%)$ - Table 1.

Of the newborns, $52.5 \%$ were male, and $47.5 \%$ were female.

We found that most babies (502 or 53.7\%) were born via Cesarean section. The incidence rate was 86.3 per 100 vaginal deliveries.

As shown in Table 1, $99(10.6 \%)$ were preterm babies (born before $36 \mathrm{GW}$ ).

The average birth weight of the newborns was $3181.71 \pm 395.9 \mathrm{~g}$. The proportion of newborns with low birth weight (under $2500 \mathrm{~g}$ ) was $4.6 \%$.

Mean levels of neonatal bilirubin were 172 $(14 \div 480)$. High bilirubin levels were found in 83 $(8.9 \%)$ of newborns.
It has been proven that oxygen therapy given to infants immediately after birth is related to transitory tachypnea and suppression of the respiratory center because of the anaesthetic, especially in cases of operative delivery. In our study, $15.5 \%$ or 145 of newborns were treated with oxygen for more than 3 hours.

One hundred three newborns (11.0\%) underwent antibiotic therapy during their hospital stay.

The results from OAEs showed there were 908 positive test results. Bilateral negative test results were found in $18(1.9 \%)$ newborns. In 9 newborns $(1.0 \%)$, unilateral negative test results were obtained (left ear in 5, and right ear in 4 of them).

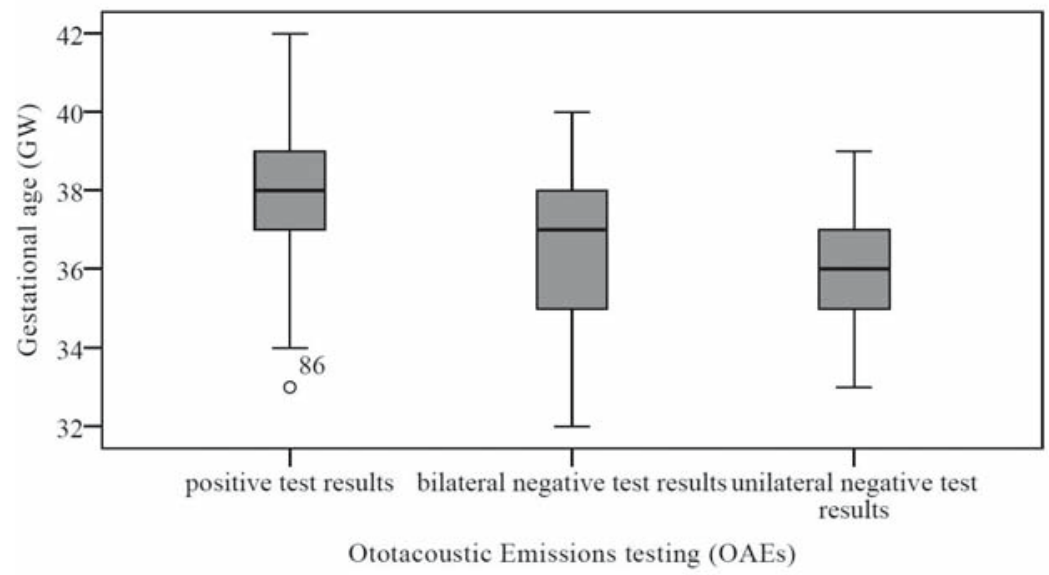

Figure 1. Mean gestational age in groups with different results of hearing screening (OAEs)

As shown in Figure 1, the mean gestational age was lower in bilateral negative test results $(36.4 \pm 2.3 \mathrm{GW})$, and unilateral negative test results $(36.1 \pm 2.0 \mathrm{GW})$ were comparable with positive test results $(38.2 \pm 1.2)$. There were statistically significant differences between studied groups $(\mathrm{F}=28.340 ; \mathrm{df}=2 ; \mathrm{p}=0.001)$.

There was a significant association between birth weight and OAEs ( $\mathrm{F}=10.649 ; \mathrm{df}=2$; $\mathrm{p}=0.001$ ). The average birth weight of the newborns was lower in cases of negative test results $(2848.7 \pm 506.5 \mathrm{~g})$, and unilateral negative test results $(2823.3 \pm 535.2 \mathrm{~g})$ compared with the group of positive test results $(3191.9 \pm 387.9 \mathrm{~g})-$ Figure 2.

There were no statistically significant differences between the type of birth and OAEs $(\mathrm{p}=0.945)$.

Mean bilirubin values were significantly higher in the newborns with hearing impairments, as compared with the group without hearing impairments (Kruskal-Wallis test $=48.467$; $\mathrm{df}=2$; $\mathrm{p}=0.001$ ).

Among the newborns, in whom OAEs showed hearing impairments, the proportion of those treated with oxygen was twice as high as in the ones not treated with oxygen $\left(\chi^{2}=64.007\right.$; $\mathrm{df}=2 ; \mathrm{p}=0.001$ ).

Also, there was a significant association between antibiotic therapy and OAEs $\left(\chi^{2}=112.969 ; \mathrm{df}=2 ; \mathrm{p}=0.001\right)$. The newborns, in whom OAEs showed negative test results $(72.2 \%)$ or unilateral negative test results $(77.8 \%)$, received 2-3 times more often oxygen therapy, as compared with the group with positive test results: $22.2 \%$ or $27.8 \%$, respectively (Figure 4). 
Atanasova K, et al. Epidemiological study on the incidence of hearing impairment ...

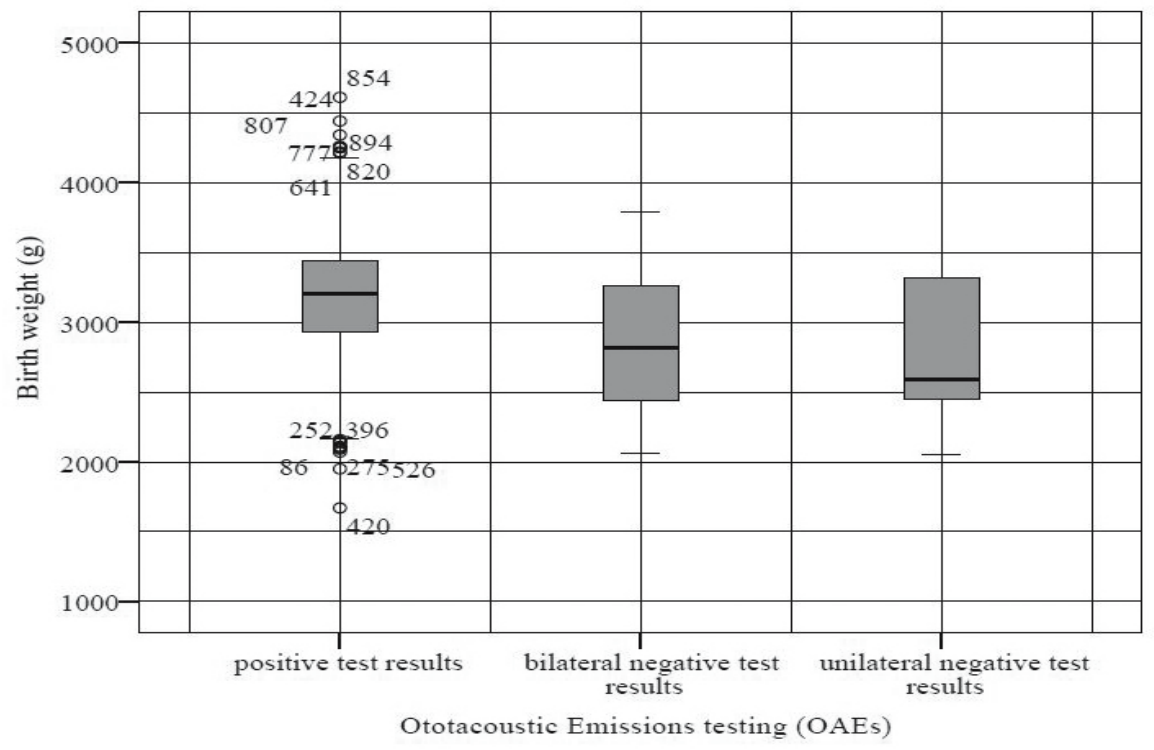

Figure 2. Average birth weight in groups with different results of hearing screening (OAEs)

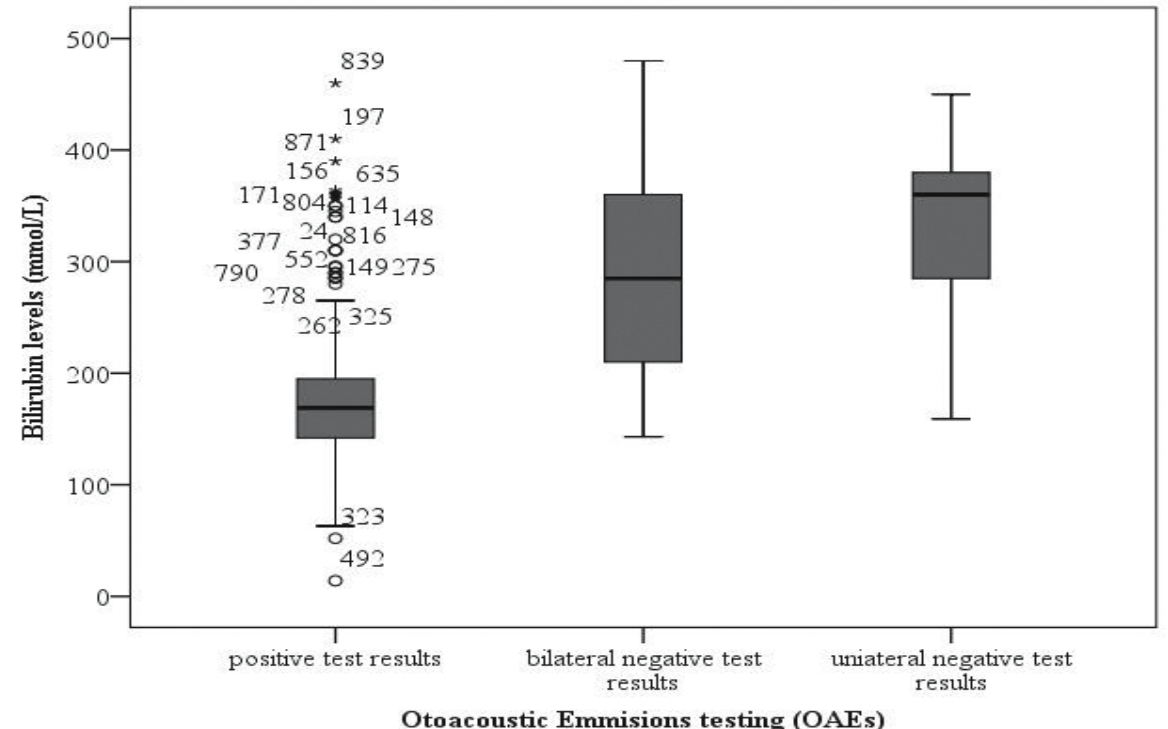

Figure 3. Mean neonatal bilirubin levels in groups with different results of hearing screening (OAEs)

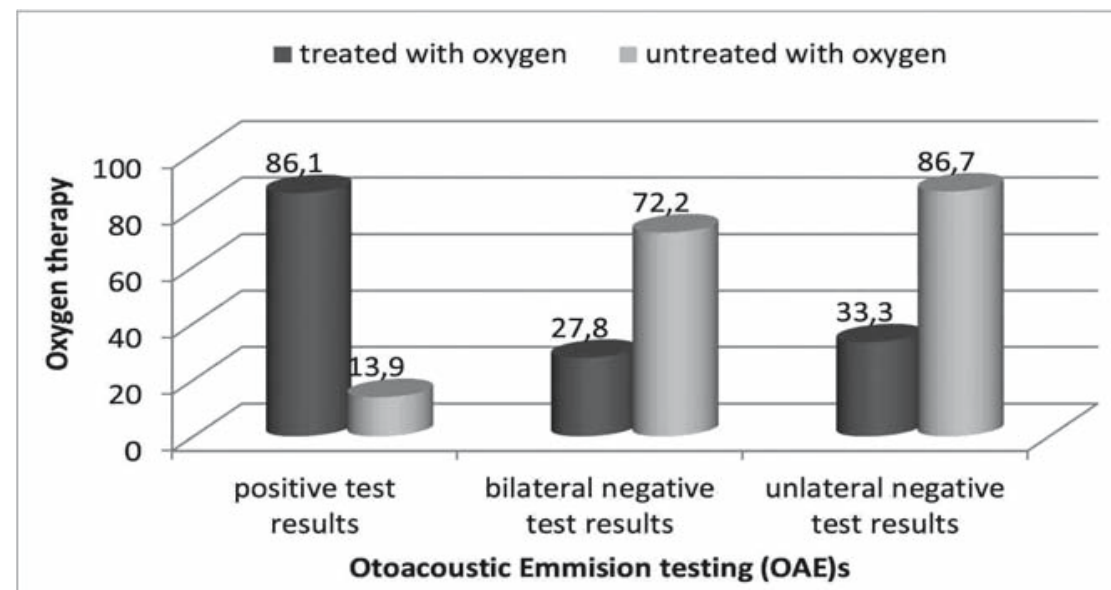

Figure 4. Distribution of the newborns according to oxygen therapy and results of hearing screening (OAEs), \% 




Figure 5. Distribution of the newborns according to antibiotic therapy and results of hearing screening (OAEs), \%

\section{Discussion}

Using the OAEs test is a safe and very fast method for early diagnosis of a hearing loss in newborns. It was highly effective and showed good sensitivity to defining the groups with RFs $[9,10]$.

This study aimed to explore the incidence of congenital hearing impairment in the Pleven district for two years. Our results showed a high diagnostic value of the screening test performed. Of all the 935 children tested, we found abnormalities in 18 children who were followed-up during the second stage of the study. Only two cases continued to demonstrate a negative result, and we referred them for further diagnostic clarification. This screening test is not intended to detect central hearing damage (due to dysfunction of projections from the brainstem to auditory cortex). Since we introduced stimuli through the external auditory canal, we supposed that any presence of amniotic fluid or problems in the middle ear could affect the test results. Researchers from Nigeria and South Africa have reported a higher percentage of cases diagnosed with hearing impairment. This percentage could be attributed to the fact that the first tests in these studies were not carried out by specialists and trained staff $[11,12]$.

In Tehran, two different tests (OAE and ABR) have been applied, and the published results regarding the incidence of hearing impairment have shown significant differences $[13,14]$. These findings demonstrate that a well- considered selection of a proper test is necessary for optimizing the results because negative results of the OAEs test affect more than one risk factor. Other studies with a large number of newborns have also made this conclusion [15]. Our study has found that low birth weight is often associated with high serum bilirubin levels, and the combined effect leads to a negative result.

\section{Conclusions}

Early diagnosis of congenital hearing impairment is of great significance for later development and social adaptation of affected children [16] and screening tests for all newborns is important. The high sensitivity of the test, along with relatively short application time, would allow its routine use in neonatal settings. Screening results would also contribute to better observation of children in specified higher-risk groups and their periodical monitoring until the age of 6 months.

\section{Acknowledgements}

This study is not part of a scientific project.

\section{References}

1. World Health Organization. Deafness and hearing loss. [Internet] [cited 2019 Jul 1]. Available from: https://www.who.int/newsroom/fact-sheets/detail/deafness-and-hearingloss.

2. Mukari SZ, Tan KY, Abdullah A. A pilot project on hospital-based universal newborn hearing screening: Llessons learned. Int $\mathrm{J}$ Pediatr 
Otorhinolaryngol. 2006;70(5):843-51.

3. Coates H, Gifkins K. Diagnostic tests, newborn hearing screening. Aust Prescr. 2003;26(4):824.

4. Cunningham M, Cox EO. Committee on Practice and Ambulatory Medicine and the Section on Otolaryngology and Bronchoesophagology. Hearing assessment in infants and children: recommendations beyond neonatal screening. Pediatrics. 2003;111(2):436-40.

5. Cristobal R, Oghalai JS. Hearing loss in children with very low birth weight: current review of epidemiology and pathophysiology. Arch Dis Child Fetal Neonatal Ed. 2008;93(6):F462-8.

6. Finitzo T, Albright K, O’Neal J. The newborn with hearing loss: detection in the nursery. Pediatrics. 1998;102(6):1452-60.

7. Lima GM, Marba ST, Santos MF. Hearing screening in neonatal intensive care unit. Pediatric (Rio J) 2006;82(2):110-4.

8. Bielecki I, Horbulewicz A, Wolan T. Prevalence and risk factors for auditory neuropathy spectrum disorder in a screened newborn population at risk for hearing loss. Int J Pediatr Otorhinolaryngol. 2012;76(11):1668-70.

9. Hoth S, Neumann K, Weissschuh H, Bräunert J, Böttcher P, Hornberger C, et al. Universal newborn hearing screening. Methodical aspects. HNO. 2009;57:29-36.

10. Sequa JM, Collar J, Lorente L, Oller A, Morant $\mathrm{M}$, Peñalver $\mathrm{O}$, et al. [Results from 10-year newborn hearing screening in a secondary hospital]. Pediatrics. 2005;63:465-70. Spanish
11. Wickremasinghe AC, Risley RJ, Kuzniewicz MW, Wu YW, Walsh EM, Wi S, et al. Risk of sensorineural hearing loss and bilirubin exchange transfusion thresholds. Pediatrics. 2015;136(3):505-12.

12. Brownell WE.. Outer hair cell electromotility and otoacoustic emissions. Ear Hear. 1990;11(2):82-92.

13. Olusanya BO, Wirz SL, Luxon LM. Community-based infant hearing screening for early detection of permanent hearing loss in Lagos, Nigeria: a cross-sectional study. Bull World Health Organ. 2008;86(12):956-63.

14. Yousefi J, Ajalloueyan M, Amirsalari S, Hassanali Fard M. The specificity and sensitivity of transient otoacustic emission in neonatal hearing screening compared with diagnostic test of auditory brain stem response in tehran hospitals; Iran J Pediatr. 2013;23(2):199-204.

15. Ari-Even Roth D, Hildesheimer M, MaayanMetzger A, Muchnik C, Hamburger A, Mazkeret R, et al. Low prevalence of hearing impairment among very low birthweight infants as detected by universal neonatal hearing screening. Arch Dis Child Fetal Neonatal Ed. 2006 Jul;91(4):F257-62.

16. Todorova Y, Valkov A, ,Duhlenski B, Nikolov G, Atanasova K ,Elkina S. et al. [Use of Shoe Box iPad iOS - based play audiometry as a hearing impairment screening tool for preschool children]. Pediatry. .2017;50(1)41-5. Bulgarian. 